\title{
Isomerization Polymerization of 2-Oxazoline. I. Preparation of Unsubstituted 2-Oxazoline Polymer
}

\author{
Takeo SAegusa, Hiroharu Ikeda, and Hiroyasu FujII \\ Department of Synthetic Chemistry, Kyoto University, \\ Kyoto, Japan.
}

(Received May 20, 1971)

\begin{abstract}
Pure unsubstituted 2-oxazoline (OXZ) was first prepared in good yields by modifying Wenker's method. ${ }^{1}$ OXZ was found to polymerize by cationic catalyst in an aprotic polar solvent to give a solid polymer. The polymerization of OXZ in less-polar solvents gave polymer in much decreased yields. Lewis acids such as $\mathrm{BF}_{3} \mathrm{OEt}_{2}$ and $\mathrm{SbF}_{5}$, sulfonates, sulfate esters, mineral acids, and alkyl iodide were effective as the polymerization catalyst. But metal chlorides such as $\mathbf{S n C l}_{4}$ and $\mathbf{S b C l}_{5}$ were ineffective. The polymer was a white powder, which was soluble in water and insoluble in most organic solvents. The polymer was shown to be crystalline by X-ray diffraction diagram $\left(\mathrm{mp} c a .210^{\circ} \mathrm{C}\right)$. The molecular structure of the polymer proved to be $\operatorname{poly}(N$-formylethyleneimine) by NMR and IR spectra. Alkaline hydrolysis of poly-OXZ gave crystalline polyethyleneimine $\left(\mathrm{mp} 58.5^{\circ} \mathrm{C}\right)$.
\end{abstract}

KEY WORDS 2-Oxazoline / Isomerization Polymerization / Cationic Polymerization / Poly $(N$-formylethyleneimine) / Crystal Polyethyleneimine /

Several 2-substituted-2-oxazolines have been polymerized at elevated temperatures by cationic catalysts to solid polymers having the structures of $\operatorname{poly}(N$-acylethyleneimine $) .{ }^{2-5}$ So far as we know, there has been no study on the polymerization of unsubstituted 2-oxazoline (OXZ). OXZ itself was synthesized for the first time by Wenker ${ }^{1}$ only in poor yields. In addition, the purity of OXZ was not high. We have improved the Wenker procedure and prepared OXZ in higher yields. Interestingly pure OXZ was successfully polymerized to solid polymer at lower temperatures than those of 2-substituted monomers.

\section{EXPERIMENTAL}

\section{Reagents}

Monoethanolamine, methyl formate, and thionyl chloride were commercial reagents and used without further purification. All solvents except for di- $n$-butyl ether were purified by distillation under nitrogen atmosphere and dried on molecular sieves 4A. Di- $n$-butyl ether was dried on metallic sodium and distilled. $\mathrm{BF}_{3} \mathrm{OEt}_{2}, \mathrm{SnCl}_{4}$, $\mathrm{SbCl}_{5}, \mathrm{TiCl}_{4}$, methyl tosylate, dimethyl sulfate, and methyl iodide were purified by distillation.
Commercial $p$-toluenesulfonic acid and $\mathrm{AlCl}_{3}$ were dried in vacuo at $50^{\circ} \mathrm{C}$ prior to use. Commercial reagents of concd sulfuric acid and $\mathrm{SbF}_{5}$ were used without further purification.

\section{Preparation of 2-Oxazoline $(O X Z)$ \\ $N$-( $\beta$-Chloroethyl)formamide 2}

Fifty grams $(0.42 \mathrm{~mol})$ of thionyl chloride were added dropwise under cooling to a stirred solution of $37.4 \mathrm{~g}(0.42 \mathrm{~mol})$ of $N$-( $\beta$-hydroxyethyl)formamide $1^{6}$ in $40 \mathrm{~m} l$ of DMF. The mixture was then heated at $40-45^{\circ} \mathrm{C}$ under reduced pressure with nitrogen bubbling for $30 \mathrm{~min}$, and subjected to distillation under reduced pressure. Compound 2 was obtained as a colorless liquid $(30.3 \mathrm{~g}, 67 \%)$ : bp $104-105^{\circ} \mathrm{C}(3 \mathrm{~mm})$; NMR

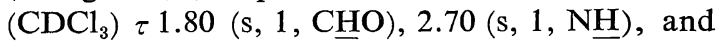
$6.35\left(\mathrm{~m}, 4, \mathrm{CH}_{2}\right)$. Anal. Calcd for $\mathrm{C}_{3} \mathrm{H}_{5} \mathrm{ClNO}$ : $\mathrm{C}, 33.51 ; \mathrm{H}, 5.62 ; \mathrm{Cl}, 32.97 ; \mathrm{N}, 13.02 ; \mathrm{O}, 14.88$. Found: C, 33.49; H, 5.70; Cl, 32.88; N, 12.99; O, 14.60 .

\section{$O X Z$}

To $600 \mathrm{~g}$ of $50-\%$ aqueous solution of $\mathrm{KOH}$ was added $183 \mathrm{~g}(1.7 \mathrm{~mol})$ of 2 at $10^{\circ} \mathrm{C}$ with stirring. The mixture was kept at $15-18^{\circ} \mathrm{C}$ for about $5 \mathrm{~min}$ and the crude $\mathrm{OXZ}$ was collected 


\section{T. SAegusa, H. Ikeda, and H. FujiI.}

in a cold trap under $10 \mathrm{mmHg}$. To the distillate $(150 \mathrm{~g}), 85 \mathrm{~g}$ of $\mathrm{KOH}$ pellets were added under cooling with ice. The dried $\mathrm{OXZ}$ was distilled in vacuo. The treatment with $\mathrm{KOH}$ pellets was repeated to give $80 \mathrm{~g}$ of $\mathrm{OXZ}$, which was then treated with molecular sieves 4A followed by distilation in vacuo. The yield was $76 \mathrm{~g}(63 \%)$, and the purity was examined by GLPC (No detectable impurity was observed). Anal. Calcd for $\mathrm{C}_{3} \mathrm{H}_{5} \mathrm{NO}: \mathrm{C}, 50.69 ; \mathrm{H}, 7.09 ; \mathrm{N}$, 19.71. Found: C, 50.42; H, 7.18; N, 19.74 .

\section{Polymerization of $O X Z$}

Polymerization was carried out in a sealed tube at $80^{\circ} \mathrm{C}$ for $5 \mathrm{hr}$. As the polymerization progressed, the polymer precipitated as a white powder. After polymerization, an excess amount of methanol was added to the reaction mixture and the polymer was filtered and dried in vacuo. Anal. Calcd for $\left(\mathrm{C}_{3} \mathrm{H}_{5} \mathrm{NO}\right)_{n}$ : C, 50.69; H, 7.09; $\mathrm{N}, 19.71 ; \mathrm{O}, 22.51$. Found: C, 50.98; H, 7.16; N, 19.07; O, 22.97.

\section{Alkaline Hydrolysis of Polymer}

To a solution of $0.606 \mathrm{~g}$ of the polymer in $7 \mathrm{~m} l$ of water was added $0.61 \mathrm{~g}$ of $\mathrm{NaOH}$. The homogeneous solution was stirred at $98^{\circ} \mathrm{C}$ for $3 \mathrm{hr}$. When the solution was cooled to room temperature, white solid precipitated, which was crushed after the addition of $30 \mathrm{~m} l$ of water. The material was washed thoroughly with water until the washings became neutral. The precipitate was recrystallized twice from water and dried in vacuo for $48 \mathrm{hr}$ to give $0.313 \mathrm{~g}(85 \%)$ of white powder: $\mathrm{mp} 58.5^{\circ} \mathrm{C}$; $\mathrm{NMR}\left(\mathrm{CD}_{3} \mathrm{OD}\right)$ $\tau 7.25\left(\mathrm{~s}, 1, \mathrm{CH}_{2} \mathrm{NCH}_{2}\right)$. Anal. Calcd for $\left(\mathrm{C}_{2} \mathrm{H}_{5} \mathrm{~N}\right)_{n}$ : $\mathrm{C}, 55.77 ; \mathrm{H}, 11.70 ; \mathrm{N}, 32.53$. Found: $\mathrm{C}, 56.0$; $\mathrm{H}, 11.8 ; \mathrm{N}, 32.2$.

\section{The NMR Spectra}

NMR spectra were taken on a Varian T-60 instrument using tetramethylsilane (for $\mathrm{CDCl}_{3}$ ) or 3-(trimethylsilyl)-1-propanesulfonic acid sodium salt (for $\mathrm{D}_{2} \mathrm{O}$ ) as an internal standard.

\section{$X$-Ray Diffraction}

$\mathrm{X}$-ray diffraction diagrams of the powdery polymer were taken by using Rigaku Denki Model SG-7.

\section{Molecular Weight and Viscosity}

The molecular weight of the polymer was measured by a vapor pressure osmometer (HitachiPerkin-Elmer model 115) in water at $59^{\circ} \mathrm{C}$. The solution viscosity of the polymer was measured in water at $30^{\circ} \mathrm{C}$, the concentration being $1 \mathrm{~g} / \mathrm{d} l$.

\section{RESULTS AND DISCUSSION}

\section{Preparation of $O X Z$}

OXZ was synthesized according to Wenker's route. ${ }^{1}$

$$
\begin{aligned}
& \mathrm{HOCH}_{2} \mathrm{CH}_{2} \mathrm{NH}_{2} \\
& +\mathrm{HCOOEt} \longrightarrow \mathrm{HOCH}_{2} \mathrm{CH}_{2} \mathrm{NHCHO} \\
& 1 \\
& 1+\mathrm{SOCl}_{2} \longrightarrow \mathrm{ClCH}_{2} \mathrm{CH}_{2} \mathrm{NHCHO} \\
& 2 \\
& 2
\end{aligned}
$$

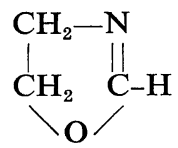

It has been reported, however, that 2 was obtained only in impure form, because of the decomposition during the distillation of the chlorinated mixture of reaction 2 . We found that reaction of 2 carried out in tertiary amine or in amide gave improved results to give pure 2 in good yields without any trouble mentioned above. Especially DMF gave the best result (67\%). Pure 2 led to the isolation of pure OXZ in the subsequent dehydrochlorination reaction $3(63 \%)$. High purity of the monomer is essential for the polymerization. The monomer sample which had been dried only by $\mathrm{KOH}$ gave a very small amount of liquid product. The high polymer was successfully obtained by using the monomer dried on molecular sieves 4A.

The IR and NMR spectra of OXZ are shown in Figures 1 and 2, respectively. The IR spectrum shows bands at $1631 \mathrm{~cm}^{-1}(>\mathrm{C}=\mathrm{N}-), 1093$ $\mathrm{cm}^{-1}(\mathrm{C}-\mathrm{O}-\mathrm{C})$, and 975,923 , and $868 \mathrm{~cm}^{-1}$ (ring skeletal), which are at lower frequencies in comparison with those of 2-substituted-2-oxazolines. ${ }^{3}$ The NMR spectrum possesses a formyl proton (singlet at $\tau 3.161 \mathrm{H}$ ), $O$-methylene protons (multiplet centered at $\tau 5.752 \mathrm{H}$ ), and $N$ methylene protons (multiplet centered at $\tau 6.21$ $2 \mathrm{H})$, respectively. The chemical shifts of methylene protons are in the same region as those of 2-substituted-2-oxazolines. ${ }^{5}$

\section{Polymerization of $O X Z$}

The polymerization of $\mathrm{OXZ}$ was carried out 
at $80^{\circ} \mathrm{C}$ in DMF using various cationic catalysts. The results are shown in Table I. Lewis acids such as $\mathrm{BF}_{3} \mathrm{OEt}_{2}$ and $\mathrm{SbF}_{5}$, sulfonate, and sulfate ester, mineral acid, and alkyl iodide were effective and gave white powdery polymers. But metal chloride such as $\mathrm{SnCl}_{4}$ and $\mathrm{SbCl}_{5}$ which have been known to initiate the polymerization of 2-substituted-2-oxazolines were ineffective in the $\mathrm{OXZ}$ polymerization. Rapid termination which was estimated from the NMR spectra of the polymerization products with these chloride

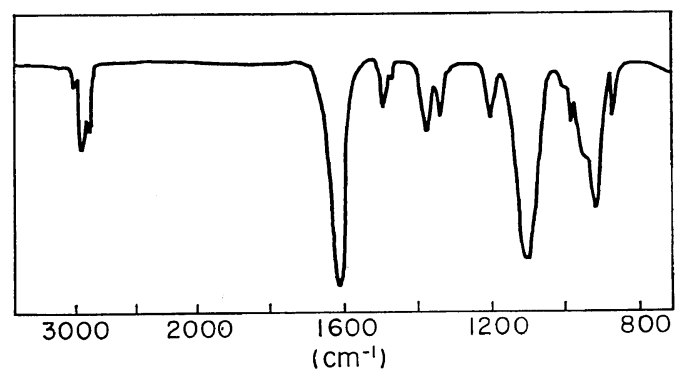

Fig. 1. IR spectrum of 2-oxazoline (neat).

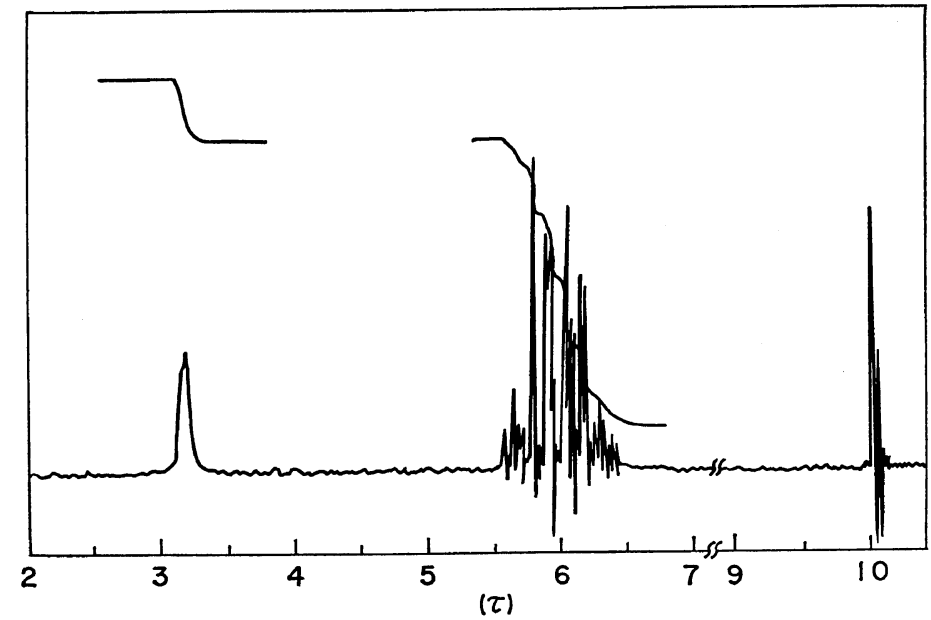

Fig. 2. NMR spectrum of 2-oxazoline (in $\mathrm{CDCl}_{3}$ ).

catalysts may be responsible for the failure of polymerization. As shown in Table II, the polymer yield was much affected by the nature of the solvent used. The polymerization in aprotic polar solvents with high dielectric constants such as DMF and acetonitrile resulted in the highest yields of polymer. Nonpolar solvents such as toluene and heptane, on the other hand, gave only a small amount of polymer. A strong base such as pyridine inhibited the polymerization. The polymerization in dimethylsulfoxide gave a large amount of liquid product with lower molecular weights in addition to a small amount of solid polymer.

\section{Characterization of Polymer}

The product polymer of $\mathrm{OXZ}$ was a white powder melting at $c a \cdot 210^{\circ} \mathrm{C}$ and was shown to be crystalline by its $\mathrm{X}$-ray diffraction diagram with a crystalline peak at $2 \theta=17.3^{\circ}$ (Figure 3).
The polymer was soluble only in water and insoluble in most organic solvents. The structure of the new polymer was established on the basis

Table I. Polymerization of 2-oxazoline (Effect of catalysts) $^{\mathrm{a}}$

\begin{tabular}{lccc}
\hline \multicolumn{1}{c}{ Catalyst $^{\mathrm{b}}$} & $\begin{array}{c}\text { Solid polymer } \\
\text { yield, } \%\end{array}$ & $\eta_{\mathrm{sp}} / c^{\mathrm{c}}$ & $\mathrm{mp},{ }^{\circ} \mathrm{C}$ \\
\hline $\mathrm{BF}_{3} \mathrm{OEt}_{2}$ & 68 & 0.20 & $207-209$ \\
$\mathrm{SbF}_{5}$ & 73 & 0.25 & $200-202$ \\
$\left(\mathrm{CH}_{3} \mathrm{O}\right)_{2} \mathrm{SO}_{2}$ & 73 & 0.23 & $210-212$ \\
$p-\mathrm{CH}_{3} \mathrm{C}_{6} \mathrm{H}_{4} \mathrm{SO}_{2} \mathrm{OCH}_{3}$ & 83 & 0.22 & $208-210$ \\
$\mathrm{H}_{2} \mathrm{SO}_{4}$ & 51 & 0.13 & $203-209$ \\
$p-\mathrm{CH}_{3} \mathrm{C}_{6} \mathrm{H}_{4} \mathrm{SO}_{3} \mathrm{H}$ & 32 & 0.14 & $200-202$ \\
$\mathrm{CH}_{3} \mathrm{I}$ & 10 & 0.08 & $193-197$ \\
\hline
\end{tabular}

a Oxazoline, $7.5-20 \mathrm{mmol}$; Catalyst, $0.01 \mathrm{~mol} /$ mol-OXZ; DMF, $4 \mathrm{ml} / \mathrm{ml}$-OXZ; at $80^{\circ} \mathrm{C}$, for $5 \mathrm{hr}$.

b $\mathrm{SnCl}_{4}, \mathrm{SbCl}_{5}, \mathrm{AlCl}_{3}$, and $\mathrm{TiCl}_{4}$ gave no polymer.

c In water at $30^{\circ} \mathrm{C}(1 \mathrm{~g} / \mathrm{d} l)$. 
Table II. Polymerization of 2-oxazoline (Effect of solvents) $^{a}$

\begin{tabular}{lccr}
\hline \multicolumn{1}{c}{ Solvent } & $\begin{array}{c}\text { Solid polymer } \\
\text { yield, } \%\end{array}$ & $\eta_{\mathrm{sp}} / \mathrm{c}^{\mathrm{b}}$ & $\mathrm{mp},{ }^{\circ} \mathrm{C}$ \\
\hline$\left(\mathrm{CH}_{3}\right)_{2} \mathrm{NCHO}$ & 68.4 & 0.20 & $207-209$ \\
$\mathrm{CH}_{3} \mathrm{CN}$ & 67.2 & $0.32^{\mathrm{c}}$ & $212-214$ \\
$\mathrm{C}_{6} \mathrm{H}_{5} \mathrm{NO}_{2}$ & 32.6 & 0.15 & $214-216$ \\
$\left(\mathrm{CH}_{3}\right)_{2} \mathrm{SO}$ & $16.2^{\mathrm{d}}$ & 0.08 & $183-187$ \\
$\mathrm{C}_{2} \mathrm{H}_{4} \mathrm{Cl} l_{2}$ & 13.2 & 0.10 & $205-207$ \\
$\left(n-\mathrm{C}_{4} \mathrm{H}_{9}\right)_{2} \mathrm{O}$ & 9.3 & 0.13 & $213-216$ \\
$\mathrm{C}_{6} \mathrm{H}_{5} \mathrm{CH}_{3}$ & 5.4 & 0.10 & $213-214$ \\
$n-\mathrm{C}_{7} \mathrm{H}_{16}$ & 4.3 & 0.12 & $213-215$ \\
$\mathrm{C}_{5} \mathrm{H}_{5} \mathrm{~N}$ & 0 & - & - \\
\hline
\end{tabular}

a 2-Oxazoline, $15 \mathrm{mmol} ; \mathrm{BF}_{3} \mathrm{OEt}_{2}, 0.15 \mathrm{mmol}$; Solvent, $4 \mathrm{ml}$; at $80^{\circ} \mathrm{C}$, for $5 \mathrm{hr}$.

b In water at $30^{\circ} \mathrm{C}(1 \mathrm{~g} / \mathrm{d} l)$.

c The molecular weight measured by vapor pressure osmometry was 2800 (in $\mathrm{H}_{2} \mathrm{O}$, at $59^{\circ} \mathrm{C}$ ).

d A large amount of liq oligomer was also formed.

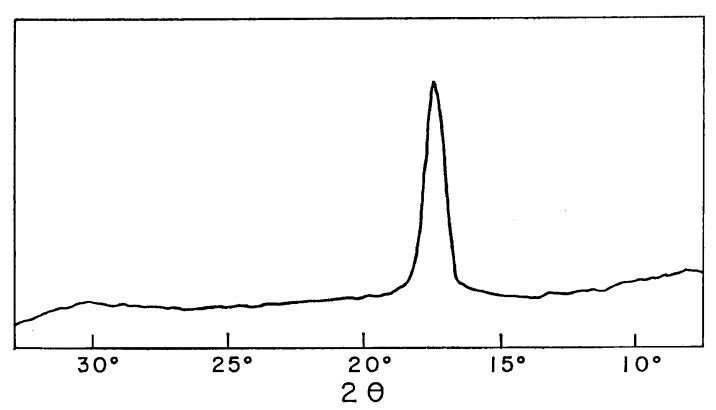

Fig. 3. X-ray diffraction diagram of 2-oxazoline polymer.

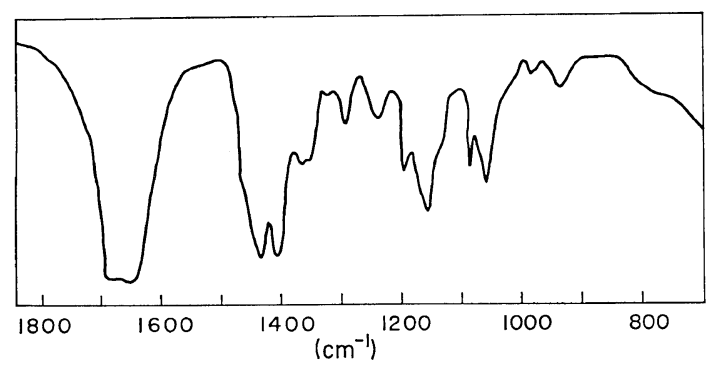

Fig. 4. IR spectrum of 2-oxazoline polymer ( $\mathrm{KBr})$.

of its NMR and IR spectra. The IR spectrum of the polymer (Figure 4) has a characteristic absorption band of tertiary amide at $1660 \mathrm{~cm}^{-1}$, and its NMR spectrum (Figure 5) shows two

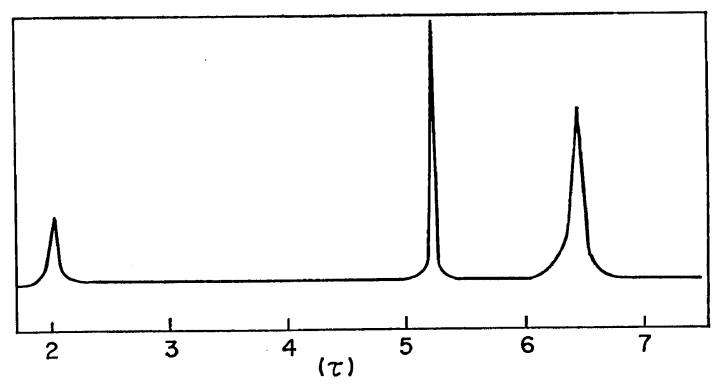

Fig. 5. NMR spectrum of 2-oxazoline polymer (in $\mathrm{D}_{2} \mathrm{O}$ ).

singlets at $\tau 2.02(1 \mathrm{H})$ and $\tau 6.45(4 \mathrm{H})$, which are reasonably assigned, respectively, to the formyl proton and $N$-methylene protons. Thus, the structure of $\operatorname{poly}(N$-formylethyleneimine) has reasonably been proposed. The formation of this type of polymer indicates that $\mathrm{OXZ}$ undergoes the cationic ring-cleavage at the $1-5$ bond followed by isomerization to amide. Moreover,

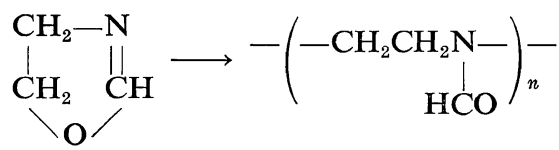

the alkaline hydrolysis of the polymer provides additional evidence for proposed structure. Poly$\mathrm{OXZ}$ was easily hydrolyzed by $\mathrm{NaOH}$ at $98^{\circ} \mathrm{C}$ to give a linear polyethyleneimine which proved to be crystalline $\left(\mathrm{mp} 58.5^{\circ} \mathrm{C}\right)$. This is the first report on crystalline polyethyleneimine. Conventional polyethyleneimines are produced by

$$
\begin{aligned}
& -\left(\begin{array}{r}
-\mathrm{CH}_{2}-\mathrm{CH}_{2}-\mathrm{N}- \\
\mathrm{HCO}
\end{array}\right)-\frac{\mathrm{NaOH}}{{ }_{98^{\circ} \mathrm{C}}} \\
& -\left(-\mathrm{CH}_{2} \mathrm{CH}_{2} \mathrm{NH}-\right)_{n}+\mathrm{HCOOH}
\end{aligned}
$$

the cationic polymerization of ethyleneimine, which are amorphous probably due to highly branched structure. ${ }^{7}$ Later, the details will be published elsewhere.

\section{REFERENCES}

1. H. Wenker, J. Amer. Chem. Soc., 60, 2152 (1938).

2. A. Tomalia and D. P. Sheetz, J. Polym. Sci. Part A-1, 4, 2253 (1966).

3. W. Seeliger, Angew. Chem., 78, 613, 913 (1966). 
Isomerization Polymerization of 2-Oxazoline

4. T. Kagiya, S. Narisawa, T. Maeda, and K. Fukui, 6. G. F. D'Alelio and E. E. Reid, J. Amer. Chem. Polym. Letters, 4, 441 (1966). Soc., 59, 111 (1937).

5. T. G. Bassiri, A. Levy, and M. Litt, Polym. 7. G. D. Jones, D. C. MacWilliams, and N. A. Letters, 5, 871 (1967). Braxtor, J. Org. Chem., 30, 1994 (1965). 